\title{
Quantitative analysis of abyssal hills in the Atlantic Ocean: A correlation between inferred crustal thickness and extensional faulting
}

\author{
John A. Goff \\ University of Texas Institute for Geophysics, Austin \\ Brian E. Tucholke, Jian Lin, and Gary E. Jaroslow \\ Woods Hole Oceanographic Institution, Woods Hole, Massachusetts \\ Martin C. Kleinrock \\ Vanderbilt University, Nashville, Tennessee
}

\begin{abstract}
A recent cruise to the Office of Naval Research Atlantic Natural Laboratory obtained $\sim 100 \%$ Hydrosweep bathymetric coverage, >200\% Hawaii MR1 (HMR1) side scan coverage, gravity and magnetics over an area spanning three ridge segments along axis $\left(\sim 25^{\circ} 25^{\prime} \mathrm{N}\right.$ to $\left.\sim 27^{\circ} 10^{\prime} \mathrm{N}\right)$, and crustal ages from 0 to $26-30 \mathrm{Ma}(\sim 400 \mathrm{~km})$ on the west flank of the Mid-Atlantic Ridge. This data set represents a first opportunity for an extensive regional analysis of abyssal hill morphology created at a slow spreading ridge. The primary purpose of this work is to investigate the relationship between abyssal hill morphology and the properties of the ridge crest at which they were formed. We apply the method of Goff and Jordan [1988] for the estimation of twodimensional statistical properties of abyssal hill morphology from the gridded Hydrosweep bathymetry. Important abyssal hill parameters derived from this analysis include root-meansquare (rms) height, characteristic width, and plan view aspect ratio. The analysis is partitioned into two substudies: (1) analysis of near-axis ( $<7 \mathrm{Ma}$ ) abyssal hills for each of the three segments and (2) analysis of temporal variations ( $2-29 \mathrm{Ma})$ in abyssal hill morphology along the run of the south segment. The results of this analysis are compared and correlated with analysis of the gravity data and preliminary determination of faulting characteristics based on HMR1 side scan data. Principal results of this study are: (1) Abyssal hill morphology within the study region is strongly influenced by the inside-outside corner geometry of the mid-ocean ridge segments; abyssal hills originating at inside corners have larger rms height and characteristic width and smaller plan view aspect ratio than those originating at outside corners. (2) The residual mantle Bouguer gravity anomaly is positively correlated with intersegment and along-flow-line variations in rms height and characteristic width, and it is negatively correlated with plan view aspect ratio. From this result, we infer that lower-relief, narrower, and more elongated abyssal hills are produced when the crust being generated is thicker. (3) Intersegment variations in near-axis rms height negatively correlate with average fault density as determined from analysis of HMR 1 side scan imagery.
\end{abstract}

\section{Introduction}

The process of abyssal hill formation at mid-ocean ridge crests is a poorly understood component of the ridge system. Abyssal hills are complex and chaotic in nature and as such present a unique set of challenges for geologic and quantitative characterization and for physical modeling of the processes that create them. Quantitative characterization of abyssal hills has long been studied, but it has received much more attention in recent years [e.g., Krause and Menard, 1965; Menard and Mammerickx, 1967; McDonald and Katz, 1969; Bell, 1975, 1978; Fox and Hayes, 1985; Gilbert and Malinverno, 1988; Goff and Jordan, 1988; Malinverno and Pockalny, 1990; Goff, 1991, 1992; Malinverno, 1991; Hayes and Kane, 1991; Goff et al., 1993;

Copyright 1995 by the American Geophysical Union.

Paper number $95 \mathrm{JB} 02510$.

0148-0227/95/95JB-02510\$05.00
Neumann and Forsyth, 1995]. Many studies have investigated the geologic structure associated with axial faulting and volcanism, which are the primary mechanisms of abyssal hill formation (see Shaw and Lin [1993] and Tucholke and Lin [1994] for up-todate and thorough reference lists for Mid-Atlantic Ridge (MAR) studies). Few studies, however, have yet attempted to formulate physical models of abyssal hill formation which satisfy quantitative and/or geological observational constraints [Schouten and Denham, 1983; Malinverno and Gilbert 1989; Malinverno and Cowie, 1993; Shaw and Lin, 1993]. This is due in part to the complicated nature of abyssal hill faulting and volcanism and in part to the dearth, until recently, of high-resolution off-axis bathymetry and geophysical data which help constrain the relationship between abyssal hills and axial conditions at the time of accretion. This paper continues the work of quantitative characterization of abyssal hill morphology and provides constraints for physical models of abyssal hill formation. Previous contributions have related abyssal hill morphology to spreading rate variations 


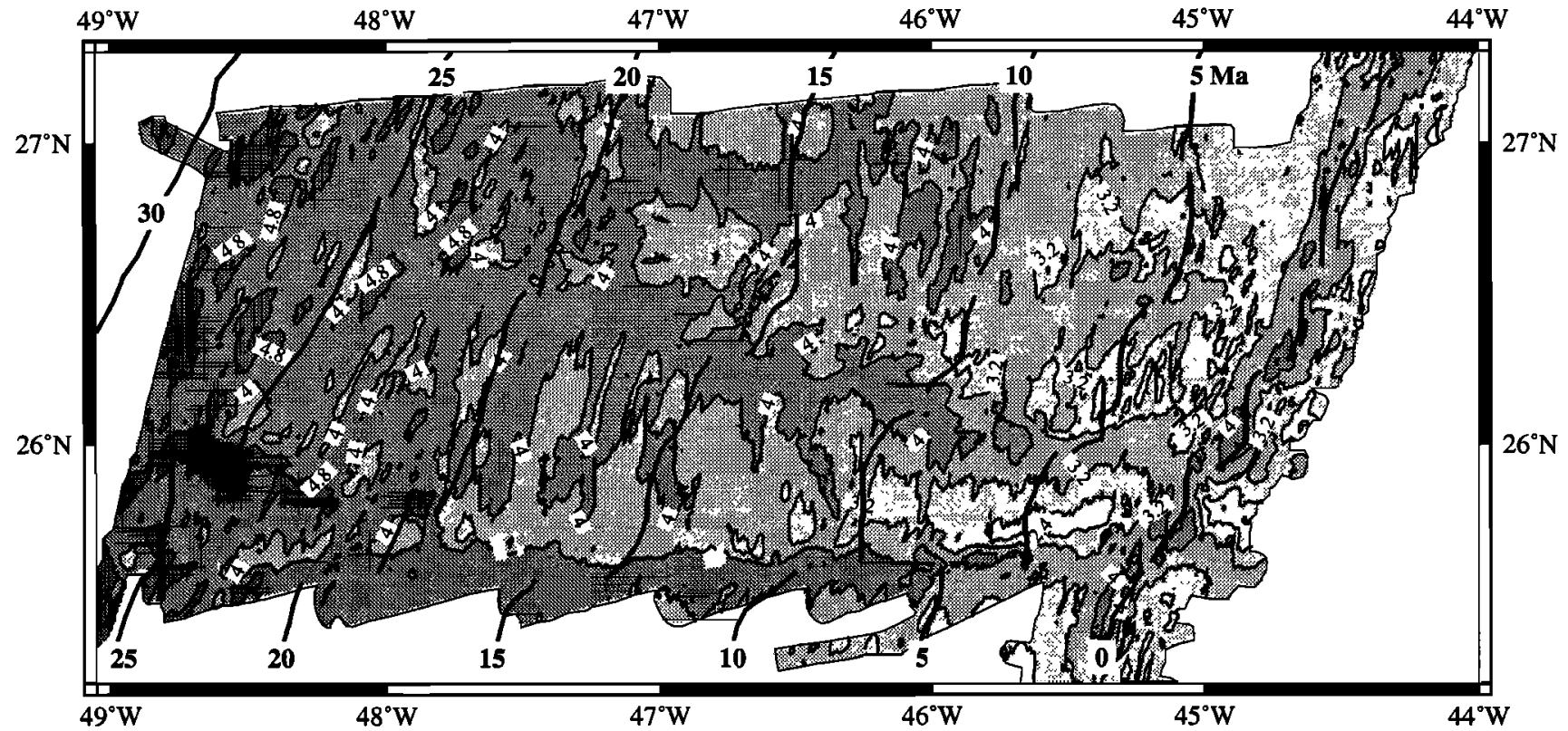

Figure 1. Simplified bathymetry (0.8-km contour interval) of the survey area, with seafloor isochrons shown at 5m.y. intervals. Isochrons are broken at segment boundaries, which are shown in Figure 2.

[Menard, 1967; Malinverno, 1991; Hayes and Kane, 1991; Goff, $1991,1992]$ and related abyssal hill morphology to ridge segmentation at fast spreading rates [Goff, 1991; Goff et al. 1993]. Our study expands on this work by relating abyssal hill morphology to ridge segmentation and temporal variability at slow spreading rates.

Our principal data set consists of Hydrosweep swath bathymetry [Chayes et al., 1991] collected on a recent geophysical cruise to the Office of Naval Research (ONR) Atlantic Natural Laboratory [Tucholke et al., 1992] aboard $R /$ Maurice Ewing. This survey obtained nearly $100 \%$ Hydrosweep bathymetric coverage as well as gravity, magnetic, and $>200 \%$ Hawaii MR1 (HMR1) side scan sonar coverage in a region extending from near the Mid-Atlantic Ridge (MAR) axis westward $\sim 400 \mathrm{~km}$

\section{Near-Axis Data}

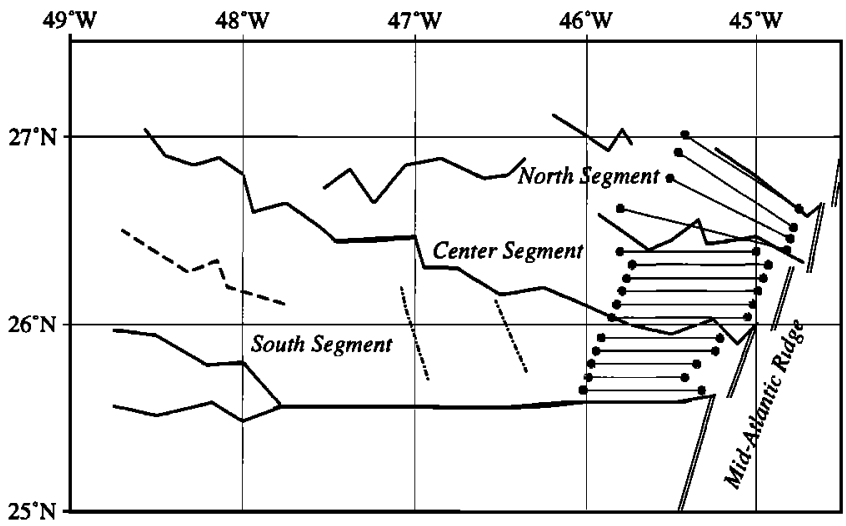

Figure 2a. Map of simplified segment boundaries surveyed during the $R / V$ Ewing cruise EW9208. Locations of the near-axis swaths used for parameter estimation are indicated by line seg. ments terminated by dots. The swath data sets are sampled from gridded bathymetric data and are $7.5 \mathrm{~km}$ in width. The dashed line in the western part of the southern segment locates a smalloffset, secondary discontinuity. The long-short dashed lines indicate likely pseudofaults created by propagating ridges. to 26-30 Ma crust. The ridge-flank crust in this region consists of three main segments (south, center, and north segments; Figures 1 and 2) which have developed between long-lived, small-offset $(\leq 30 \mathrm{~km}$ ) ridge axis discontinuities. The south segment is the longest lived ( $\geq 29$ m.y.) and exhibits a continuous record of relatively stable evolution. The center and north segments have had shorter lives ( $\leq 20$ m.y.), their bounding discontinuities have small (to zero) offsets (Figure 1), and they are tectonically more complex than the south segment.

We use the methodology of Goff and Jordan [1988, 1989] and Goff [1990] to estimate statistical parameters of abyssal hill morphology in the survey area through formalized inversion of bathymetric data. Principal estimated parameters include the second-order statistical parameters root-mean-square (rms) height, characteristic width, and plan view aspect ratio. The

\section{South Segment Data}

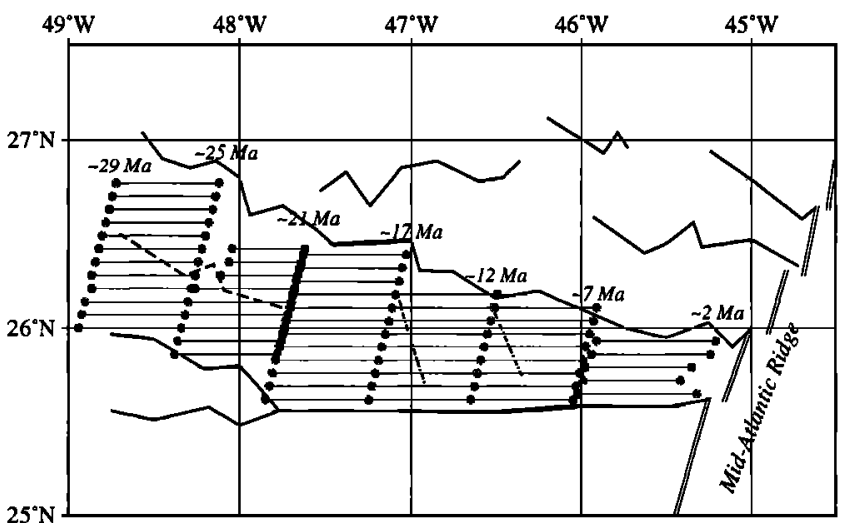

Figure 2b. Locations of off-axis swaths used within the south segment (see Figure 2a for details). With minor, short-term exceptions, all offsets at the discontinuities bounding the south segment are right lateral (as is the offset at the secondary discontinuity at 29-21 Ma); thus inside corner crust is in the southern part of the segment. 
analysis is partitioned into two substudies (Figure 2): (1) analysis of near-axis $(<7 \mathrm{Ma})$ bathymetric data for each of the three segments, enabling a comparison between the present-day ridge axis and the most recently created abyssal hills and (2) analysis of bathymetric data within the long-lived south segment, enabling an analysis of temporal variability (from -2-29 Ma) in abyssal hill morphology.

Results of the abyssal hill parameter estimation are compared with other geophysical data from the survey area, including residual mantle Bouguer gravity anomaly (RMBA), and fault identifications from side scan sonar data. The RMBA provides an estimate of crustal thickness [e.g., Kuo and Forsyth, 1988; Lin et al., 1990; Lin and Phipps Morgan, 1992; Tucholke and Lin, 1994], and by inference the temperature structure of the spreading axis at the time of crustal accretion [e.g., Su et al., 1994]. This information helps to identify changes in the axial environment that might have caused changes in abyssal hill morphology. The fault identifications from side scan data provide an independent measure of faulting, one of the two principal abyssal hill forming processes.

Quantitative analysis of abyssal hill morphology has begun to place observational constraints on the process of generation of seafloor and crust at mid-ocean ridge systems. Several previous studies [Menard, 1967; Malinverno, 1991; Hayes and Kane; 1991; Goff, 1991, 1992] showed that abyssal hill rms heights are generally larger at slower spreading rates. This correlation can be attributed, at least in part, to the spreading rate dependence of axial thermal structure [Phipps Morgan et al., 1987; Shaw and Lin, 1994] and the consequent effect on lithospheric strength and faulting (see discussion by Goff [1991]). The dependence of rms height on spreading rate is, however, only one small part of the relationship between abyssal hills and the ridge system at which they were formed. For example, Goff [1991] found that abyssal hills formed at the fast spreading East Pacific Rise (EPR) possess shape and texture characteristics that are fundamentally different from those produced at the slow spreading MAR. This observation suggests that differences in abyssal hill forming processes between the two mid-ocean ridges go well beyond simple scaling (although it remains to be determined precisely what those additional differences are).

A significant amount of variation in abyssal hill morphology not attributable to spreading rate variation also occurs on a regional scale (i.e., tens to hundreds of kilometers),. Studies by Goff [1991] and Goff et al. [1993] on multibeam data from the flanks of the EPR show that much of this variation is controlled by segmentation of the mid-ocean ridge crest. In particular, abyssal hill $\mathrm{ms}$ height tends to be largest toward the ends of a segment (bounded by first- or second-order discontinuities) and smallest toward the middle. This pattern is well correlated with what is interpreted from morphology and gravity constraints to be focused mantle upwelling beneath the ridge axis [e.g., Cochran et al., 1993; Scheirer and Macdonald, 1993; Wang and Cochran, 1993], implying an association of larger-throw faults with colder axial mantle temperatures near segment ends [Goff, 1991; Goff et al., 1993].

The present study demonstrates that MAR intrasegment abyssal hill variation is primarily correlated to inside-outside corner location [Tucholke et al., 1992; Lin et al., 1992; Tucholke and Lin, 1994] rather than to focused mantle upwelling inferred from along-axis variations in crustal thickness [e.g., Detrick et al., 1995] or dynamic modeling [e.g., Sparks et al., 1993]. Variations in MAR abyssal hill morphology along the run of segments (Figure 3 ) and between segments are found to be large, implying strong temporal and segment-to-segment variations, respectively, in axial processes. These variations in abyssal hill properties (most notably rms height) are correlated to variations in the RMBA (consistent with earlier findings by Shaw and Lin [1993] and Neumann and Forsyth [1995]) and, where not unduly masked by sediment cover, to fault density as interpreted from HMR1 side scan sonar data. We infer from this a correlation of abyssal hill faulting with the temporal and spatial variations in crustal thickness and/or mantle temperature structure at the ridge axis. Both this interpretation and earlier ones from EPR studies suggest that the strength and thickness of the lithosphere are the dominant physical factors which control the formation of abyssal hills.

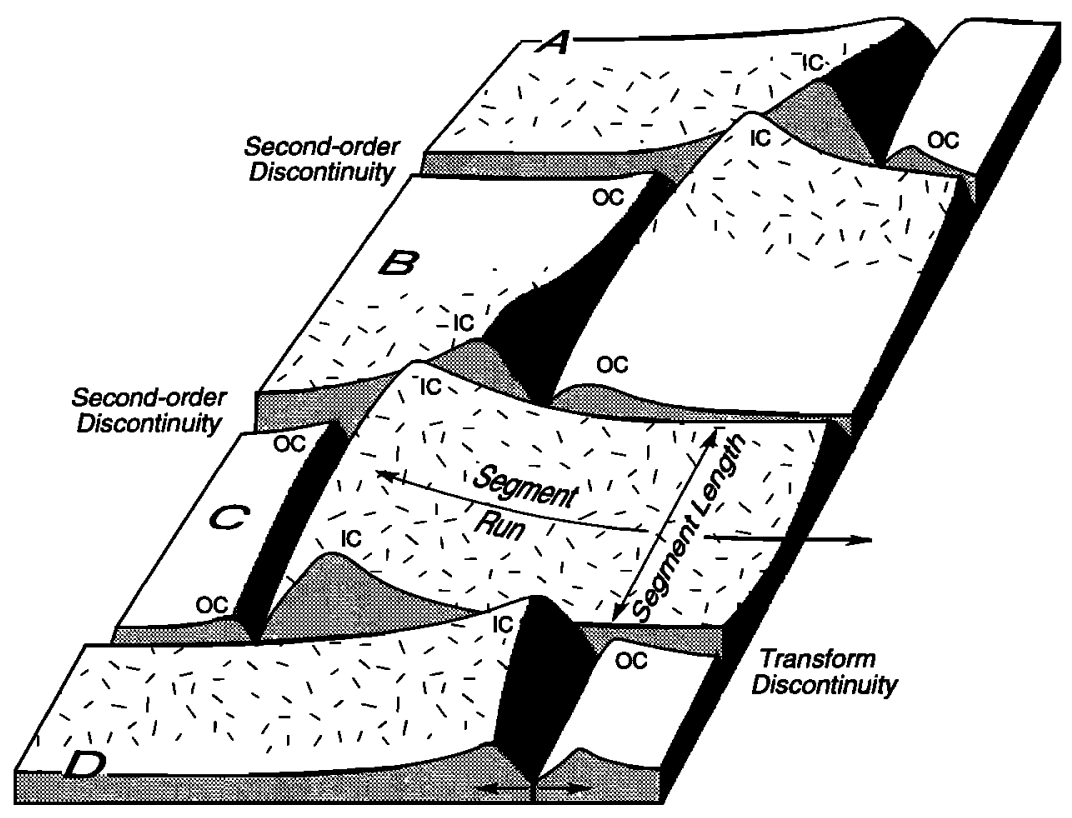

Figure 3. Schematic sketch defining geometry of inside corner crust (IC, stippled region), outside corner crust (OC), segment length and run for ridge segments bounded by transform and nontransform discontinuities in slowspreading crust [from Tucholke and Lin, 1994]. 


\section{Stochastic Characterization}

The stochastic model used to characterize second-order statistics of abyssal hill morphology and the procedure for inverting model parameters from multibeam bathymetric data are detailed by Goff and Jordan [1988, 1989] and Goff [1990]. The method takes as input a swath of multibeam data, or the gridded data set, and produces as output estimations of relevant physical parameters with estimated uncertainties. To obtain optimal data orientation relative to segment boundaries, only gridded Hydrosweep data (gridded at $200-\mathrm{m}$ spacing) were used for this analysis. Sections of the gridded data chosen for analysis consisted of elongate rectangular areas $7.5 \mathrm{~km}$ wide and $50-100 \mathrm{~km}$ long, oriented subparallel to plate flow lines (see Figure 2).

For simplicity, we refer to each elongated-box sample of the gridded data set as a "swath" of data (this term also emphasizes similarity to multibeam sampling). Two constraints are placed on swaths chosen for input: (1) They are straight and long enough to produce well-resolved estimations of the statistical parameters [Goff and Jordan, 1989], and (2) the morphology sampled does not include major seamounts or major segment boundaries as determined from bathymetry, gravity, and magnetic data. Because of differences in decorrelation distances (the distance between two points required for each to be considered an independent sample), longer data records are required to make reasonable parameter estimations in the Atlantic compared to the Pacific. For example, whereas a 20 - to $25-\mathrm{km}$-long swath of data might be sufficient for flanks of the EPR, a $60-$ to $75-\mathrm{km}$-long swath is necessary for the flanks of the MAR.

Sample swaths are oriented generally along flow line paths for two reasons: (1) This orientation maximizes resolution of alongisochron variability associated with ridge segmentation, and (2) the along-flow-line direction represents the direction of shortest decorrelation distance and therefore maximizes parameter resolution versus sample size. Wherever heterogeneity exists on scales shorter than the length of the swath, the results represent an average of the properties sampled. For example, propagator pseudofaults are contained within some of the swaths used for this analysis (Figure 2) (B. Tucholke et al., manuscript in preparation, 1995). These swaths likely contain a mixture of seafloor types, including pseudofault morphology, abyssal hills adjacent to the pseudofault which are influenced or modified by the pseudofault, and abyssal hills unaffected by the pseudofault. The spatial resolution of the statistical estimation is insufficient to make these distinctions, so care must be taken in interpretation of results. The output physical parameters include the following:

1. The rms height is the average variation of bathymetry from the mean depth.

2. The lineament azimuth is trend of abyssal hill lineaments.

3. The characteristic scale is the dominant length of features along a profile. It is defined by the width of the covariance function along the profile direction [Goff and Jordan, 1988]. Perpendicular to the grain, it is called the characteristic width of abyssal hills, and parallel to the grain, it is called the characteristic length.

4. The aspect ratio is the characteristic plan view shape of the abyssal hills, defined by the ratio between characteristic length and width.

5. The Hausdorff (fractal) dimension is a measure of roughness. It is defined by the asymptotic properties of the covariance function at small lag. An increase in fractal dimension represents an increase in roughness, with the limiting cases of 2 and 3 corresponding to a random field with continuous derivative (Euclidean surface) and one which is space filling (Peano surface), respectively.

These parameters and their uncertainties form an objective basis to distinguish differences from one region to another. What these parameters cannot do at present is tell us, for example, that a certain region is dominated either by extensional tectonism or constructional volcanism. These processes are dissimilar, and it is not unreasonable to expect that the morphologies they produce will have characteristic differences which can be detected with the estimated stochastic model parameters. However, to make this distinction we will need to "ground-truth" the statistics, i.e., match statistical characteristics with geologic characteristics. This can be accomplished in part with the HMR1 side scan sonar data, from which can be identified steep, unsedimented scarps interpreted as normal faults (G. Jaroslow et al., manuscript in preparation, 1995).

In addition to the second-order statistical parameters listed above, estimates can be made of higher-order (i.e., non-Gaussian) statistical parameters such as skewness, tilt, and kurtosis (peakiness). In practice, however, for a regional study such as presented here, only the second-order parameters rms height, lineament azimuth, characteristic width and plan view aspect ratio are well enough resolved that their variation due to geologic processes within the study area exceeds their resolution errors. Hence this study focuses on only these parameters (with the exception of lineament azimuth, which is the subject of a separate study).

\section{Near-Axis Analysis}

Figure 2a shows the paths of individual swaths used for parameter estimation in the near-axis data set. These data extend from -1-2 Ma to -6-7 Ma crustal ages. We assume that the abyssal hills sampled by these swaths were formed by processes similar to those that are now active at zero age. Hence these data allow us to correlate abyssal hill characteristics with known ridge axis processes [Tucholke and Lin, 1994; B. Tucholke et al., manuscript in preparation, 1995].

\section{RMS Heights}

RMS heights estimated from near-axis data (Figure 2a) are plotted with 1- $\sigma$ error bars in Figure 4. There are two principal observations. First, variation in rms heights within each ridge segment is asymmetric, with greater rms heights skewed toward the southern parts of the segment. Each of these segments is

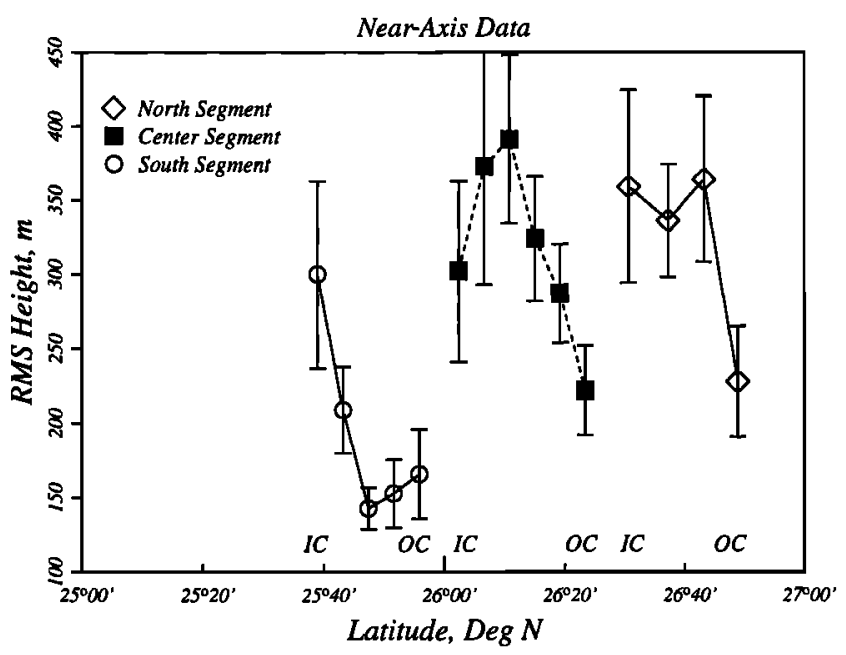

Figure 4. RMS height of abyssal hills estimated from the nearaxis swaths (Figure 2a), plotted as functions of average latitude over the length of the swath. Vertical bars represent $1-\sigma$ error estimates. "IC" and "OC" indicate locations of inner corners and outer corners, respectively. 
bounded by right-lateral discontinuities (Figure 1), so the southern portions are inside corner crust, and the northem portions are outside comer crust (Figure 3). This observation differs from that of Shaw [1992], who stated that larger faults (and consequently larger abyssal hills) tend to occur toward both ends of MAR segments. However, the Shaw [1992] study, which did not consider inside-outside corner asymmetry, demonstrated this observation by comparing a single profile through the center of a segment with a single profile over an inside corner, and the latter was used to demonstrate the behavior of segment ends in general. RMS heights do not increase monotonically going from outside to inside corners. Within the south segment, rms height tends to reach a minimum toward the middle of the segment, similar to observed variations along the EPR flank [Goff, 1991; Goff et al., 1993]. In contrast, within the center segment, maximum values are in the middle of the segment, and the sparsely sampled north segment shows no clear pattern.

The second principal observation is the large difference in rms heights between the south segment and the north and center segments. Neglecting inside and outside corner position, rms heights within the south segment are approximately half the rms heights within the center and north segments. This difference is very striking; south segment rms heights are among the lowest values seen in near-axis Atlantic abyssal hill morphology, while rms heights within the adjacent center segment are among the largest [see Goff, 1991].

\section{Characteristic Width}

Characteristic widths estimated from the near-axis data are shown with $1-\sigma$ error bars in Figure 5. This parameter is not as well resolved as rms height, so interpretation of variation are less clear. Nevertheless, we observe that as with rms heights, characteristic widths display an inside-outside comer asymmetry, and the largest characteristic widths tend to occur at inside corners (southern part of segments). The center segment has a nearly monotonic increase in characteristic width from outside to inside corner. In contrast, the south segment has a well-resolved minimum in the middle of the segment.

Unlike ms heights, there is little contrast in average characteristic width between the south segment and the center and north segments. However, the minimum characteristic width for the

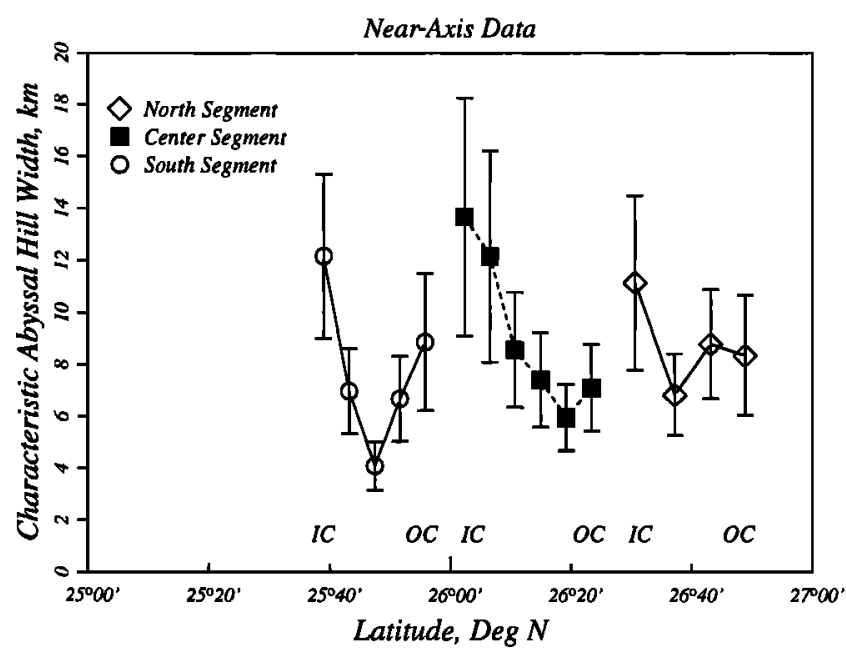

Figure 5. Characteristic widths of abyssal hills estimated from the near-axis swaths (Figure 2a), plotted as a function of average latitude over the length of the swath. Vertical bars represent $1-\sigma$ error estimates. "IC" and "OC" indicate locations of inner corners and outer corners, respectively.

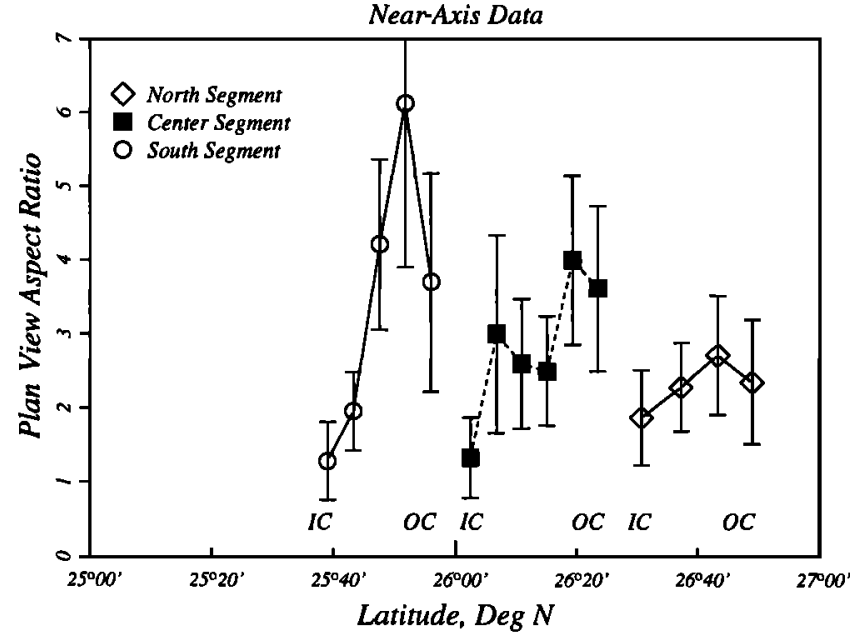

Figure 6. Plan view aspect ratios of abyssal hills estimated from the near-axis swaths (Figure 2a), plotted as a function of average latitude over the length of the swath. Vertical bars represent 1- $\sigma$ error estimates. "IC" and "OC" indicate locations of inner corners and outer corners, respectively.

south segment, which occurs in the middle of the segment, is distinctly less than that of the center and north segments.

\section{Plan View Aspect Ratio}

Plan view aspect ratios estimated from the near-axis data are shown with $1-\sigma$ error bars in Figure 6. Again, the variation in this parameter is dominated by inside-outside corner position, with the lowest aspect ratios tending to be at inside corners. For both the south and center segments, the aspect ratio near the inside corners approaches unity; i.e., there is no discernible lineation to the fabric. Neglecting the samples near the inside corner, however, we find that aspect ratios attain their highest values at the center of the outside corner part of the south segment.

\section{Comparison With Other Geophysical Constraints}

To examine the causes of variations in abyssal hill parameters noted above, here we consider correlations with other geophysical and geological data from the same area and with results and interpretations from other studies. The most consistent variation in all of our parameters is the inside-outside corner asymmetry (Figures 4-6), which is well recognized from other studies of slow spreading ridges [e.g., Karson and Dick, 1983; Severinghaus and Macdonald, 1988; Blackman and Forsyth, 1991; Tucholke et al., 1992; Tucholke and Lin, 1994; Escartin and Lin, 1995]. These authors note the following asymmetries: inside corner crust is more elevated than outside corner crust; faulting at inside corners is of higher amplitude and more irregular in pattern than at outside corners, where faults generally parallel the ridge axis; RMBAs are larger over inside comer crust than over outside corner crust, implying that inside corner crust is thinner; and basement samples of inside corners contain peridotites and gabbros more frequently than outside corners. These observations support a model in which rifting toward segment ends is accommodated in a low-angle detachment fault, with the inside corner constituting the footwall and the outside corner the hanging wall [Dick et al., 1981; Karson and Dick, 1983; Karson, 1990; Tucholke and Lin, 1994]. In this scenario, extrusives erupting at the ridge axis are emplaced principally on the outside corner hanging wall, whereas the inside comer footwall is primarily deep crustal or mantle rocks [Karson, 1990; Tucholke and Lin, 
1994]. Both hanging wall and footwall are subject to secondary, high-angle normal faulting.

A second primary observation is the large contrast in rms heights between the south segment and the center and north segments (Figure 4). Character of the segments at the spreading axis shows no strong correlation with this observation. Each segment is approximately the same length and has the same sense of offset (Figures 1 and 2). Offset length at both ends of the south and center segments is $\sim 10-15 \mathrm{~km}$, while offset length at the northern end of the north segment is $\sim 5 \mathrm{~km}$. Depth profiles of these segments along the MAR axis are shown in Figure 7. The south and center segments have similar, asymmetric profiles. The north segment profile reaches shallower depths and is more symmetric. None of these morphologic variations convincingly distinguish the south segment from the center and north segments.

The corresponding along-axis RMBA field for these three segments (J. Lin et al., manuscript in preparation, 1995) is shown in Figure 8. In these profiles, we do see marked differences between the south segment and the center and north segments. Over the south segment, there is a deep low in the RMBA which is roughly circular in two-dimensional planform (a "bull's eye" gravity low [Kuo and Forsyth, 1988; Lin et al., 1990]). RMBA signals such as these are interpreted to indicate either focused mantle upwelling and/or thickened crust beneath the segment center [Kuo and Forsyth, 1988; Lin et al., 1990; Lin and Phipps Morgan, 1992; Sparks et al., 1993]. Both are likely true because thicker crust in the middle of the segment implies greater melt production and thus elevated mantle temperatures [e.g., Sparks et al., 1993; Su et al., 1994]. In contrast to the south segment, the center segment exhibits a much weaker RMBA low at its center (Figure 8). The RMBA profile across the north segment is highly unique among MAR segments in that it has a deep low (lower even than the southern segment anomaly), but the low is centered at the end of the segment rather than the middle. The cause of this asymmetry is uncertain.

The most convincing evidence that the south segment is or was in the recent past different than both center and north segments is provided by off-axis RMBA [Lin et al., 1992; J. Lin et al., manuscript in preparation, 1995] (Figure 9). Over the span sampled by the near-axis swaths, the RMBA for the south segment is on average $\sim 10-14 \mathrm{mGal}$ lower than for the center and north segments, implying that the southern segment has accreted crust averaging $\sim 1 \mathrm{~km}$ thicker for the past $\sim 7$ to $1 \mathrm{Ma}$. Again, this implies that the mantle temperature during accretion was greater for the south segment than for the center and north segments during this span of time [e.g., Su et al., 1994]. We therefore infer from

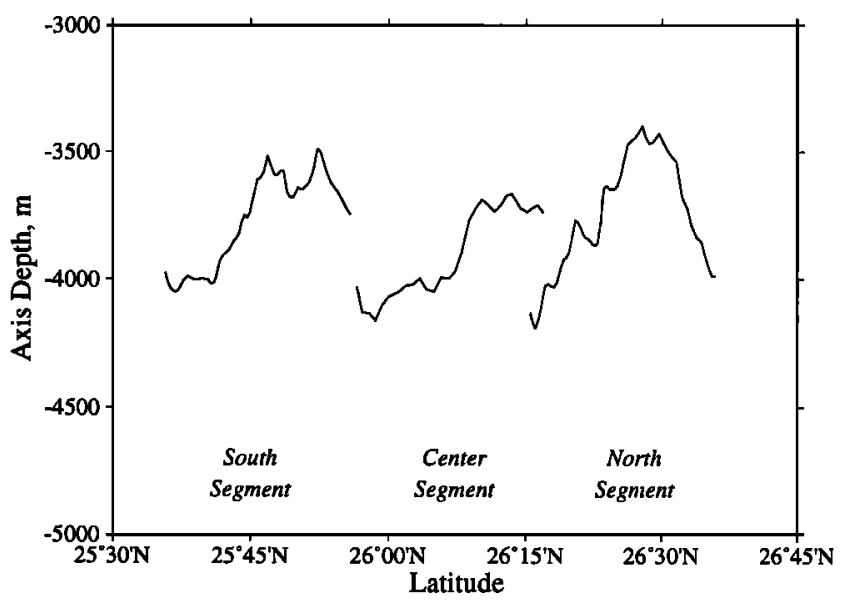

Figure 7. Bathymetry along the axis of the neovolcanic zone of the Mid-Atlantic Ridge at the eastem end of the survey area.

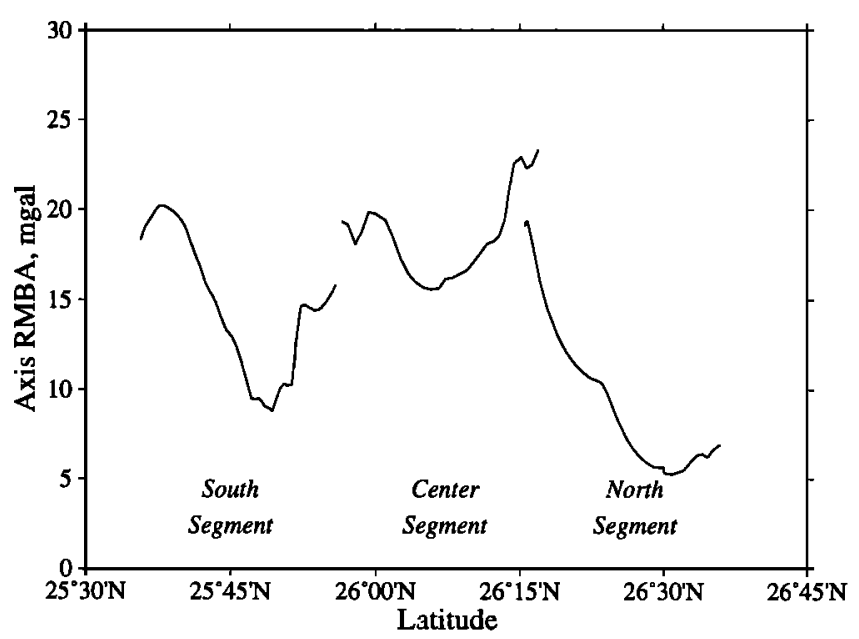

Figure 8. Residual mantle Bouguer anomaly (RMBA) (J. Lin et al., manuscript in preparation, 1995) sampled along the axis of the neovolcanic zone of the Mid-Atlantic Ridge at the eastern end of the survey area. RMBA is derived by subtracting from the free-air anomaly the following predictive components: (1) the effects of water-crust and crust-mantle interfaces, assuming a model crust of $6 \mathrm{~km}$ thickness and water, crust, and mantle densities of $1.03,2.70$, and $3.30 \mathrm{Mg} / \mathrm{m}^{3}$, respectively, and (2) the effects of mantle density changes due to lithospheric cooling [Kuo and Forsyth, 1988; Lin et al., 1990] based on a three-dimensional model of passive mantle upwelling [Phipps Morgan and Forsyth, 1988].

the intersegment comparison a negative correlation between mantle temperature/crustal thickness and the rms height of abyssal hills, and a positive correlation between mantle temperature/crustal thickness and plan view aspect ratio.

Fault density interpreted from the HMR1 side scan sonar data is also markedly different between the south segment and the center and north segments (G. Jaroslow et al., manuscript in preparation, 1995). Through the middle of each segment and spanning crustal ages $\sim 1-7 \mathrm{Ma}$, the south segment exhibits a fault density of $1.18 \pm 0.07$ faults $/ \mathrm{km}$, whereas the center and north

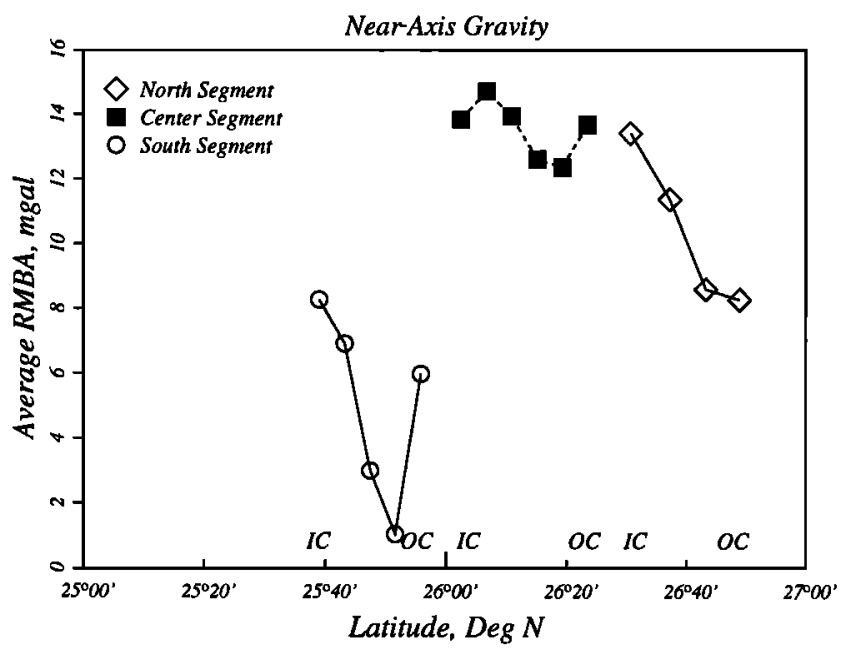

Figure 9. RMBA values associated with the near-axis swaths (Figure 2a); each plotted value represents the average of the RMBA field (see Figure 8 for details) calculated over the length of each near-axis swath. Data from J. Lin et al. (manuscript in preparation, 1995). "IC" and "OC" indicate locations of inner comers and outer corners, respectively. 
segments have significantly smaller values of $0.76 \pm 0.03$ faults $/ \mathrm{km}$ and $0.70 \pm 0.02$ faults $/ \mathrm{km}$, respectively. Comparing these values with center-of-segment parameter estimates in Figures 4-6 implies a negative correlation between fault density and both rms heights and characteristic width, as well as a positive correlation between fault density and plan-view aspect ratio.

\section{Analysis of South Segment}

Figure $2 b$ shows positions of data swaths used to analyze the full run of the south segment. These data represent a $\sim 29-\mathrm{m}$.y. record of a continuously developed spreading segment. There are, however, several second-order complexities in the evolution of the segment. At $\sim 22 \mathrm{Ma}$, the plate spreading direction rotated counter-clockwise by $\sim 9^{\circ}$ [Tucholke et al., 1992; B. Tucholke et al., manuscript in preparation, 1995). Prior to this time, a distinct but small-offset ridge axis discontinuity divided the south segment in two (dashed lines, Figure 2). This boundary has a much weaker bathymetric expression than the primary, larger-offset discontinuities bounding the south segment (solid lines, Figure 2). As we will show later, this boundary had some effect on abyssal hill morphology, but this effect was subsidiary to the gross inside-outside corner asymmetry of the full south segment. In the following text, we apply the term "secondary discontinuity" to identify this structure.

At younger crustal ages of $\sim 16 \mathrm{Ma}$ and $\sim 11 \mathrm{Ma}$, structural lineaments crosscut the abyssal hill fabric and offset the magnetic anomalies (Figures 1 and 2). These structures appear to be the result of rift-propagation events (B. Tucholke and M. Kleinrock, manuscript in preparation, 1995), and they most likely have some effect on our estimates of abyssal hill statistical properties as discussed below.

In the following analysis, we average abyssal hill parameters estimated from all swaths combined within each of a series of 4to 5-m.y. crustal age ranges (age bins). This averages out variability associated with inside-outside corner asymmetry, allowing us to investigate temporal variations in abyssal hill morphology. Also, the two southernmost (inside corner) samples within each age bin are excluded from the averaging. This maintains our focus on "normal" abyssal hills, i.e., those created on what is assumed to be full-thickness crust with well-developed, ridge-parallel faultingIn addition, we examine rms height, swath by swath, within each age bin, to determine along-isochron variation of abyssal hill character within the segment.

\section{RMS Height}

RMS heights estimated along the run of the south segment, averaged in the manner described above, are plotted in Figure 10a. There is significant variation in observed $\mathrm{rms}$ height on time scales ranging from 5 to $\sim 15$ m.y. The large rms height values in the 12-7 Ma bin appear to be influenced by the propagator pseudofault running through this region (Figure $2 b$ ). However, the pseudofault in the 17-12 Ma bin has no comparable effect; rms heights here are among the lowest values observed.

RMS heights from individual swaths within the south segment are plotted as a function of swath latitude in Figure 11 for the set of six age bins. The samples in the 29-25 and 25-21 Ma age bins cross the secondary discontinuity within the western part of the segment (Figures 2b, 11a, and $11 \mathrm{~b}$ ). Along-isochron variations in rms height display similar character within each of these six age bins. As with the near-axis data (Figure 4), there is a clear asymmetry associated with the inside-outside corner position in the segment as a whole, with larger rms heights in the southern, inside corner part; this is particularly notable in the $29-25 \mathrm{Ma}, 25$ $21 \mathrm{Ma}$, and 21-17 Ma age bins. (The large error bars on these
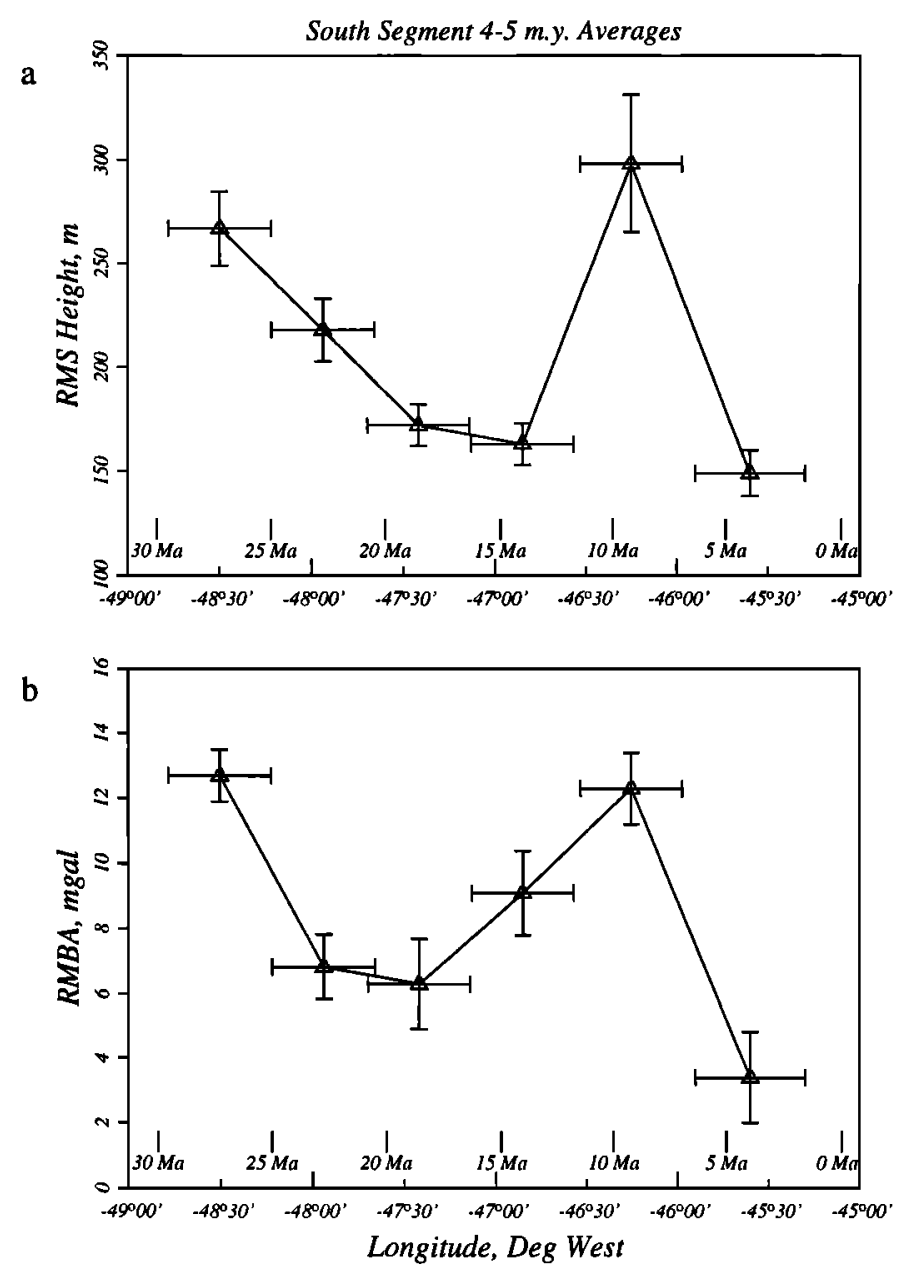

Figure 10. (a) RMS heights averaged within 4- to 5-m.y. crustal age bins over the south segment swaths (Figure 2b) (excluding the southernmost two swaths, i.e., those associated with inside corners) and plotted as a function of average longitude. (b) RMBA along the run of the south segment, averaged, as with rms heights above, to emphasize temporal variations; each plotted value represents an average of the RMBA field (see Figure 8 for details) calculated both over the length of each swath and over all swaths (excepting the southernmost two) in each age bin. Data are from J. Lin et al. (manuscript in preparation, 1995). Vertical bars represent $1-\sigma$ error estimates on the averages. Horizontal bars are approximate longitudinal span of the samples. Crustal ages are indicated.

plots are somewhat misleading, because we are making observations regarding the population of estimations rather than a single estimation. For example, a weighted linear inversion of the rms height estimations displayed in Figure $11 \mathrm{a}, 11 \mathrm{~b}$, or $11 \mathrm{c}$ resolves a negative slope (left to right) at $\sim 2 \sigma$ or better.) In the $17-12 \mathrm{Ma}$ age bin the trend is still present (mostly due to the single low rms estimate of the northernmost sample), but high rms heights also appear near the outside comer, possibly because of the propagator pseudofault. Similar propagator effects may account for the lack of any trend in the 12-7 Ma age bin.

Though the gross inside-outside comer pattern is the same, the south segment rms heights plotted for age bins 29-25 Ma, 25-21 Ma, 21-17 Ma (Figures 11a-11c) display a structure different in detail from that of the near-axis rms heights (Figure 4). Proceeding from outside to inside corner (north to south), the rms heights increase and then decrease marginally toward the middle before increasing again toward the inside corner. Though the error bars are generally large relative to this small "step" in rms 
a

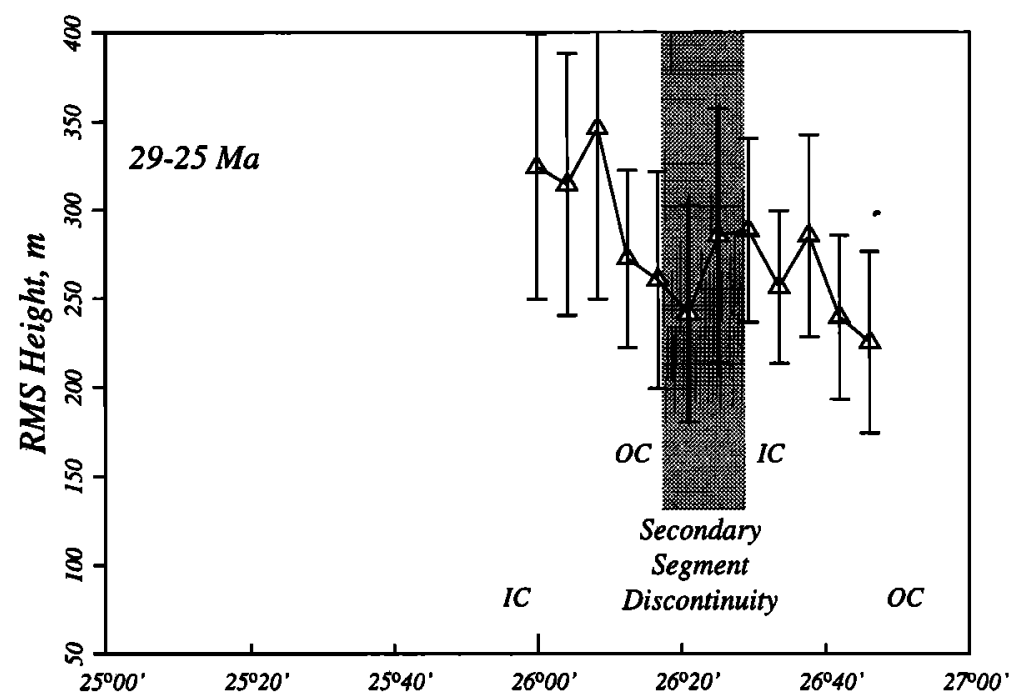

b

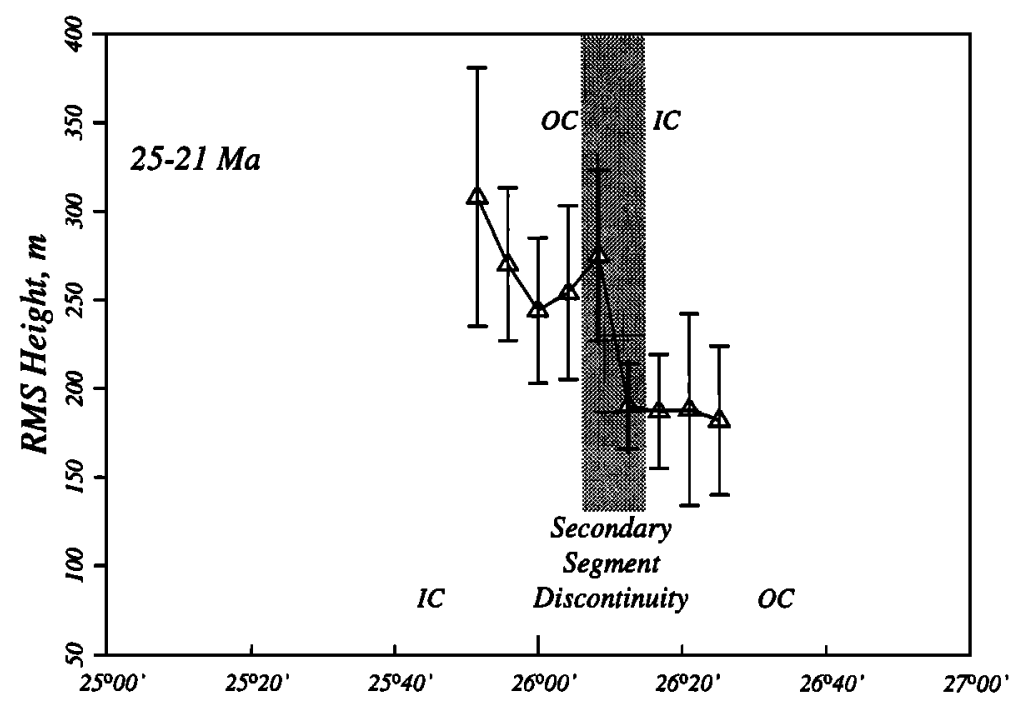

c

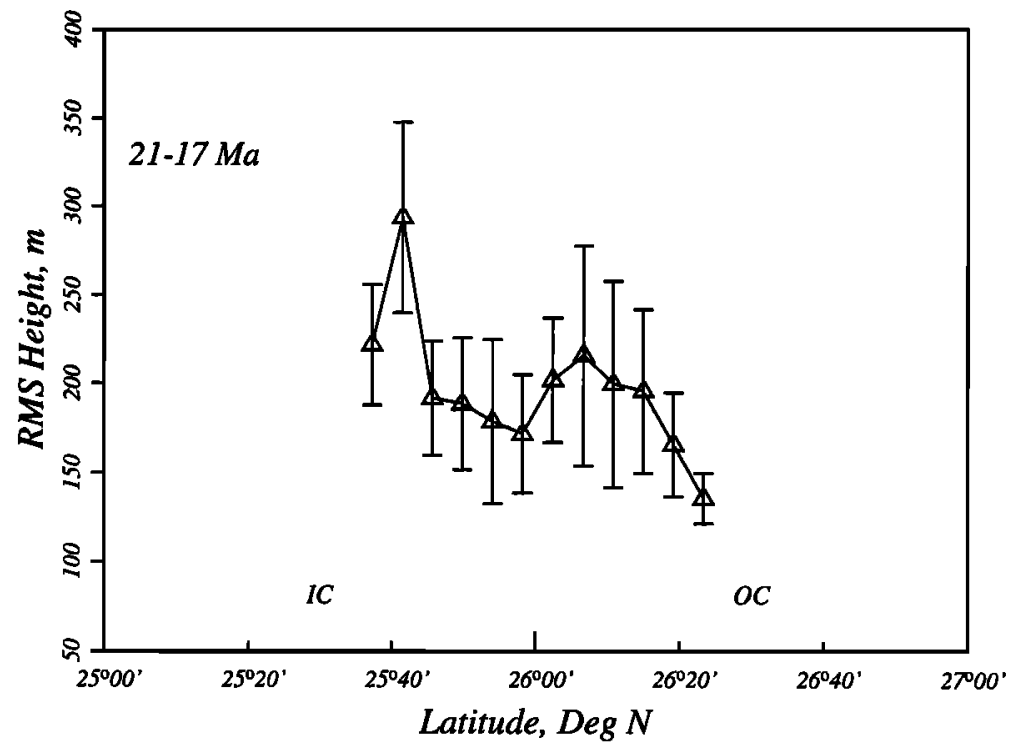

Figure 11. Swath-by-swath estimates of rms heights for six successive 4- to 5-m.y. crustal age bins in the south segment, plotted as a function of swath latitude. Vertical bars represent estimated $1-\sigma$ errors. The span of swaths which sample the small-offset secondary discontinuity with the south segment (see text) are marked by the shaded region. "IC" and "OC" indicate locations of inner corners and outer corners, respectively. 

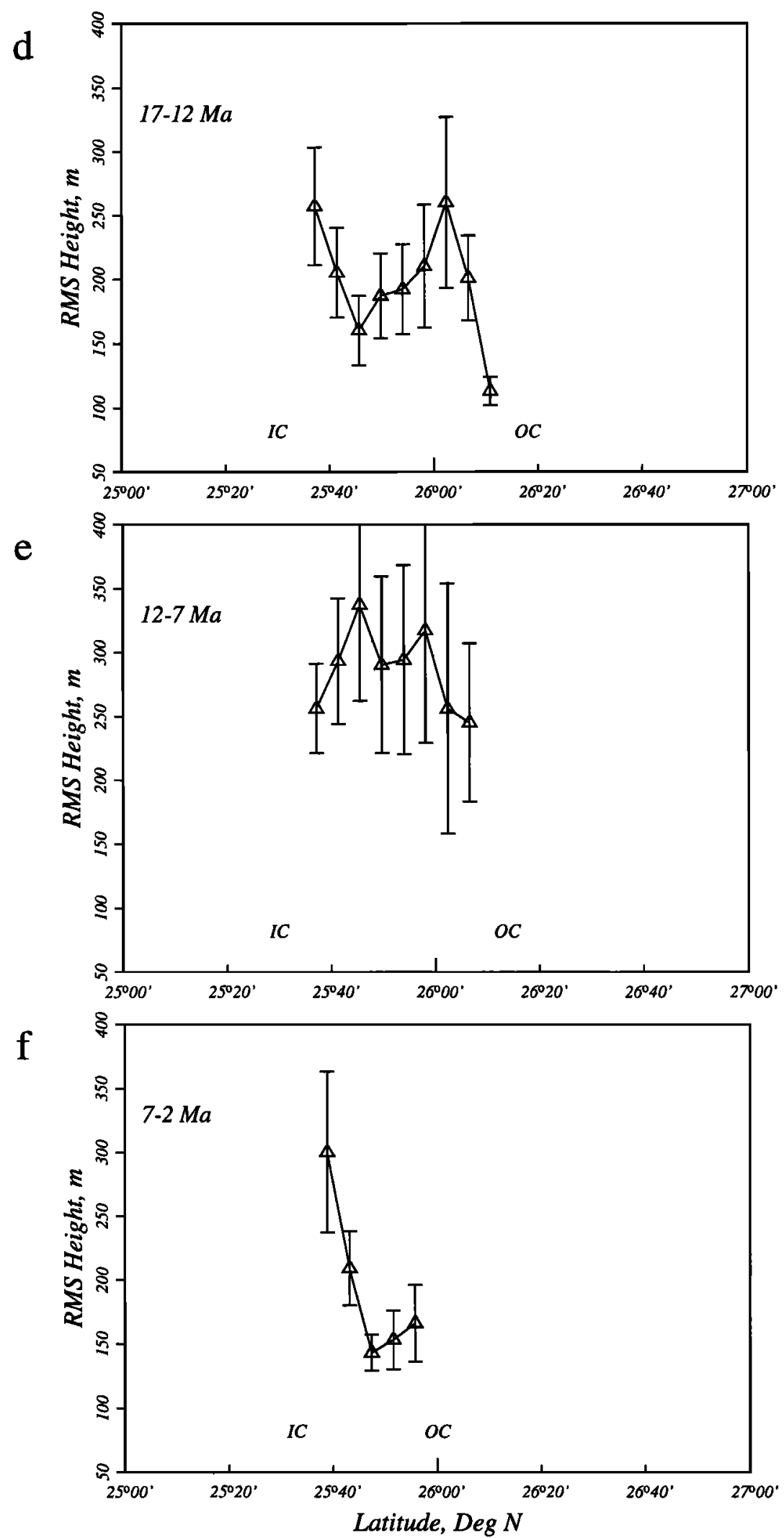

Figure 11. (continued)

height, the consistency of this feature at all three age bins suggests that it is real. In the 29-25 and 25-21 Ma age bins, the step is spatially coincident with the secondary discontinuity identified by B. Tucholke et al. (manuscript in preparation, 1995) (Figures $11 \mathrm{a}$ and 11b). The continuation of this step structure into the 21-
17 Ma age bin (Figure 11c) suggests that the secondary discontinuity influenced topography in this younger crust. However, there is no gravity, magnetic, or bathymetric evidence for continuation of the boundary (J. Lin et al., manuscript it preparation, 1995; B. Tucholke et al., manuscript it preparation, 1995). RMS 
heights within the 17-12 Ma age bin (Figure 11d) display a behavior similar to that of older age bins, i.e., a southward increase in rms height, followed by a decrease, and then an increase again toward the inside corner. However, the initial increase is large and abrupt, and it is followed by a lengthy decrease toward the inside comer; thus it does not give the appearance of a "step" in an overall outside-to-inside corner increase in rms height. This character is different from that at the secondary discontinuity, and we infer that it is related to the presence of the propagator pseudofault.

\section{Characteristic Width and Plan-View Aspect Ratio}

Characteristic widths estimated from the south segment data set and averaged for each 4- to 5-m.y. age bin are plotted in Figure 12a. Though some details differ, the gross variation in this parameter is similar to that of rms heights (Figure 10a): Both parameters start off large in the 29-25 Ma age bin, generally decrease to the 25-21 Ma, 21-17 Ma, and 17-12 Ma age bins, increase to maximum value in the 12-7 $\mathrm{Ma}$ age bin, and decrease to minimum value in the 7-2 Ma age bin.

Individual estimations of characteristic width between $29 \mathrm{Ma}$ and $12 \mathrm{Ma}$ are, like rms heights, generally larger at inside comers than at outside corners. However, there is no obvious step toward the middle of the segment as there appears to be in the rms heights. The degree of positive correlation between rms height and characteristic width is most objectively quantified by the cor-

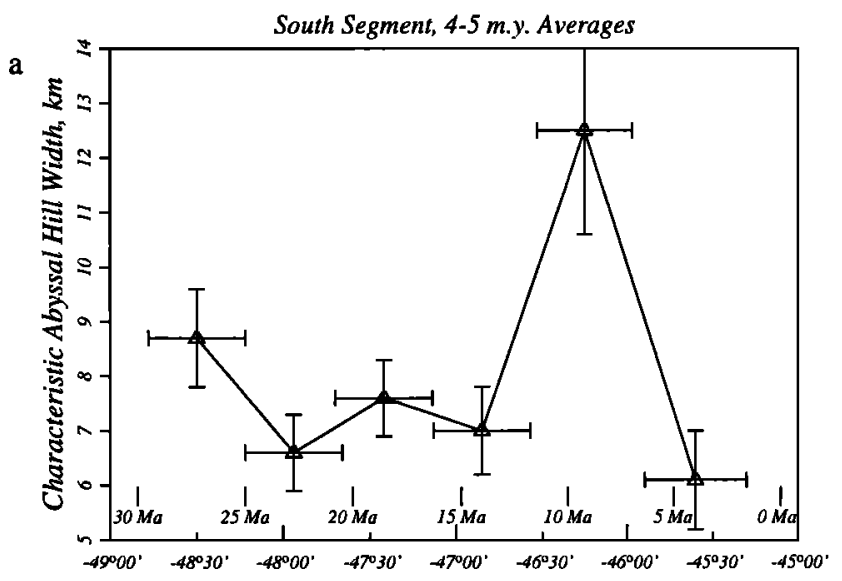

b

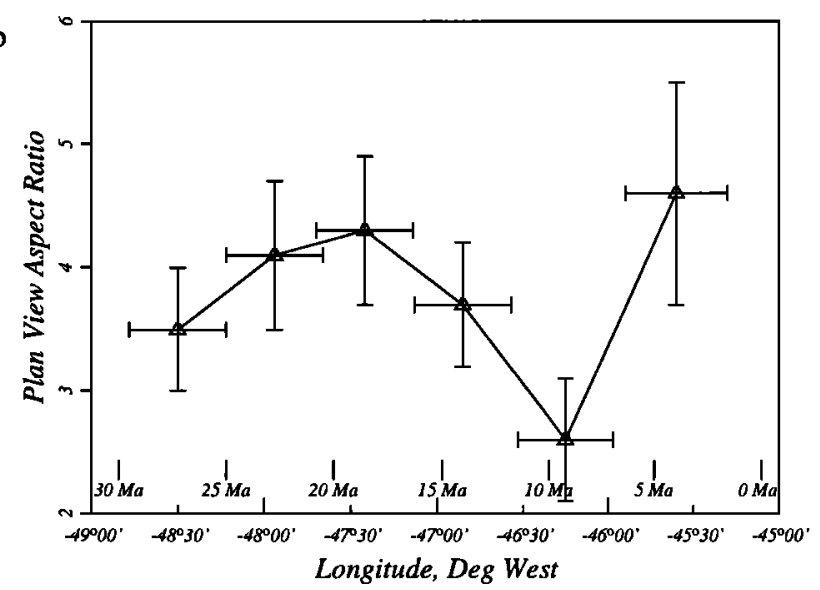

Figure 12. (a) Characteristic widths and (b) plan view aspect ratios averaged within each 4-5 m.y. crustal age bin over the south segment swath samples (Figure 2b), plotted as a function of average longitude. Vertical bars represent $1-\sigma$ error estimates on the averages. Horizontal bars represent the approximate longitudinal span of the samples. Crustal ages are also indicated. relation coefficient [see Press et al., 1989]. For either the entire data set or just the south segment data, the correlation coefficient between these two parameters is $\rho=+0.48$ with confidence $>99 \%$. Although this coefficient is not very high, it is well resolved, and it represents a minimum value because the actual correlation is degraded by random errors in both parameters. Hence it is likely that characteristic width and rms height are responding to similar physical mechanisms which control the formation of abyssal hills.

Figure $12 \mathrm{~b}$ plots plan view aspect ratios estimated from the south segment data and averaged in the manner described earlier. The pattern expressed in this plot is similar and opposite to the plots of averaged ms height and characteristic width in Figures $10 \mathrm{a}$ and 12a. Over both the near-axis and south segment data sets, rms height and plan view aspect ratio have a correlation coefficient of $\rho=-0.32$ with confidence $>99 \%$. Over just the south segment data set, the coefficient is $\rho=-0.28$ with confidence $=$ 97\%.

As with the near-axis samples (Figure 6), individual estimations of plan view aspect ratios over the entire south segment are almost uniformly smallest near the inside corner. To quantify this observation, we calculated the average aspect ratio for the southern two swaths in each segment and over every age bin shown on Figure 2, as well as the average over all remaining swaths. The near-inside-corner swaths have an average aspect ratio of $2.04 \pm 0.18$, and the remaining samples have an average aspect ratio of $3.70 \pm 0.21$, almost a factor of 2 difference.

\section{Comparison With Other Geophysical Constraints}

As in our analysis of near-axis abyssal hill morphology, we find a strong (though not perfect) positive correspondence between along-flow-line variations in RMBA and rms heights over the run of the south segment (Figures 10a and 10b). Figure 10b shows averaged RMBA over the run of the south segment (data from Lin et al., [1992] and J. Lin et al. (manuscript in preparation, 1995)). The averaging scheme, which is essentially identical to that used for RMS heights in Figure 10a, subdues RMBA variations associated with segmentation (i.e., focused upwelling, inside/outside corner asymmetry) while emphasizing variations associated with temporal variability in the accretionary process. The principal difference between Figures $10 \mathrm{a}$ and $10 \mathrm{~b}$ is that residual gravity in the 17-12 Ma age bin is large relative to the corresponding average rms height. This may indicate that the propagator pseudofault running through this region (Figure 2) has more expression in gravity signature than it does in bathymetry. Along-flow-line variations in averaged characteristic width (Figure 12a) and plan view aspect ratio (Figure 12b) (with a negative correspondence) also display similarities to the RMBA plotted in Figure 10b.

The RMBA is interpreted primarily to reflect the thickness of the crust [e.g., Kuo and Forsyth, 1988; Lin et al., 1990; Lin and Phipps Morgan, 1992; Tucholke and Lin, 1994]: RMBA lows suggest thicker crust, and RMBA highs imply thinner crust. Variations in thickness of the crust, to a first order, may in turn reflect variations in melt production and hence in mantle temperature at the axis at the time of emplacement [Lin et al., 1990; Su et al., 1994]. Thus we infer that the quantitative characteristics of abyssal hills are correlated with temporal variations in both crustal thickness and mantle temperature at the ridge axis; where mantle temperature is relatively hot and thicker crust is produced, abyssal hills generally have reduced height and are narrower and more lineated, and where the mantle temperature is cooler and thinner crust produced, abyssal hills are generally higher, wider, and less lineated.

The correlation between RMBA and abyssal hill characteristics can also be demonstrated on unaveraged estimates. Over the en- 
tire data set, the correlation coefficient between RMBA and rms height is $\rho=+0.57$ with confidence $>99 \%$. In addition to reflecting along-flow-line correlations in gravity and $\mathrm{ms}$ height, this correlation is also consistent with inside-outside comer asymmetry (larger rms heights and thinner crust at inside corners). Though less robust, well-resolved correlations can also be demonstrated between RMBA and both characteristic width $(\rho=$ +0.31 , confidence $=99 \%)$ and plan-view aspect ratio $(\rho=-0.33$, confidence $=99 \%$ ).

The negative correspondence noted earlier between abyssal hill statistical parameters and fault density (as interpreted from the HMRl side scan data) cannot be demonstrated for the entire south segment. Figure 13a plots average fault density for each age bin calculated along a flow line swath within the center of the south segment. The large increase in fault density from the 12-7 Ma to the 7-2 Ma age bins is consistent with the large increases in ms height and characteristic width and the decrease in apect ratio over the same age bins (Figure 10a), but these relationships do not continue for older crustal ages.

The discrepancy at older ages may be related to the accumulation of sediment cover, which can mask smaller faults and thus decrease observed fault density. Figure $13 \mathrm{~b}$ plots average esti-
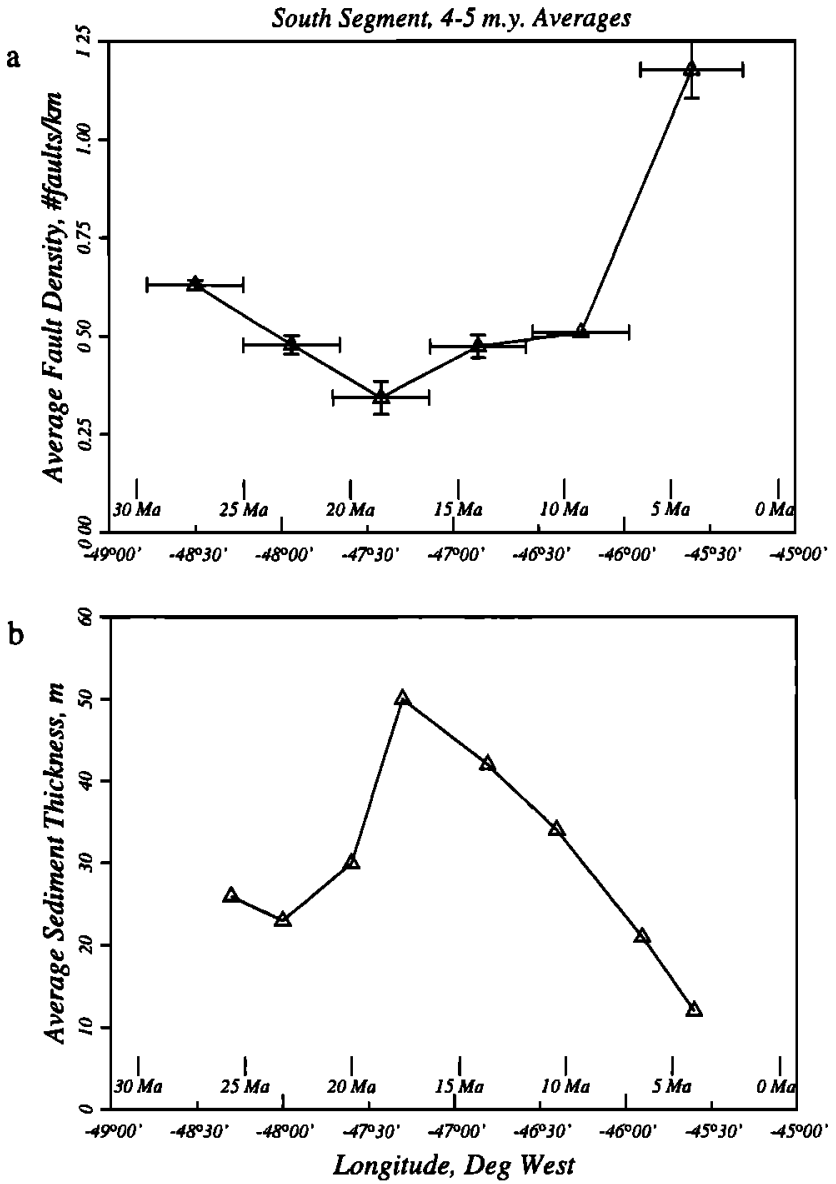

Figure 13. (a) Fault densities averaged within each 4- to 5-m.y. crustal age bin in the south segment (Figure $2 b$ ), plotted as a function of average longitude. Fault densities were calculated from HMR1 side scan sonar interpretations along a flow line corridor approximately at the center of the south segment. Vertical bars represent $1-\sigma$ error estimates on the averages. Horizontal bars represent the approximate longitudinal span of the samples. Crustal ages are also indicated. (b) Estimated average sediment thicknesses over the south segment [from Webb and Jordan, 1993]. mated sediment thickness over the south segment as derived by Webb and Jordan [1993]. Webb and Jordan [1993] created a highly innovative approach to modeling sediment accumulation based on numerical sedimentation algorithms. Comparing the model with observed bathymetry, they found that sediment loads do not increase monotonically with age within the survey area, but rather peak at an estimated $50 \mathrm{~m}$ in the range 20-15 Ma before decreasing to $-25 \mathrm{~m}$ at $-25 \mathrm{Ma}$. This observation is consistent with actual accumulations observed in seismic reflection data collected in the same region and may be explained by a hypothesized deepening of the calcite compensation depth in the late Miocene [Tucholke and Vogt, 1979; Webb and Jordan, 1993]. The variation in sediment load plotted in Figure 13b matches, in reverse, the fault densities interpreted from side scan sonar data at crustal ages $>\sim 7 \mathrm{Ma}$ (Figure 13a).

We note that the $\sim 25-\mathrm{m}$ increase in sediment load from $\sim 25$ Ma to $\sim 17 \mathrm{Ma}$ (Figure 13b) may partially explain the variation in rms height over corresponding age bins (Figure 10a). However, H. Webb (personal communication, 1993) estimates that, even for the most strongly ponded sediments within the study area, an average sediment load of $L$ will cause a decrease in topographic rms height at most by $L$ and more likely by $\sim L / 2$. Therefore sedimentation is not likely a significant factor in the observed $-100-\mathrm{m}$ decrease in average rms height from $\sim 29 \mathrm{Ma}$ to $\sim 17 \mathrm{Ma}$.

\section{Results and Discussion}

Principal results of statistical analysis of the Hydrosweep bathymetry within the ONR Atlantic Natural Lab are as follows:

1. Near-axis intrasegment variation in abyssal hill morphology is dominated by asymmetry between inside and outside corners; abyssal hills produced on inside corner crust have larger rms height and characteristic width and smaller plan view aspect ratios than abyssal hills produced at outside corners.

2. Inside to outside comer asymmetry in abyssal hill morphology generally persists in crust of the south segment over the full range of crustal ages sampled in the survey. However, within the age bins 29-25 Ma and 25-21 Ma, the outside to inside corner increase in rms heights is slightly offset by a negative step near the segment center, and this step appears to be associated with a secondary, small-offset discontinuity. The step in rms height persists into the 21-17 Ma age bin, although the secondary discontinuity has no signature in gravity, magnetics, or crustal geomorphology.

3. Along-flow-line and intersegment variations in abyssal hill morphology correlate with variations in RMBA, consistent with earlier results from Shaw and Lin [1993] and Neumann and Forsyth [1995]. These variations appear to correlate to variations in crustal thickness and thus by inference to melt generation and temperature of the mantle at the time of crustal accretion; lower-relief, narrower, and more lineated abyssal hills are produced when the crust being generated is thicker (i.e., when the mantle beneath the axis is hotter).

4. Near-axis estimates of average fault density (as determined from analysis of HMR1 side scan imagery) computed through the center of each segment correlate with colocated estimates of statistical parameters: negatively with both rms height and characteristic width and positively with plan view aspect ratio.

We discuss these results below.

\section{Abyssal Hill Segmentation}

Goff [1991] documented numerous textural differences between MAR- and EPR-produced abyssal hills. To these differences we add another: the along-isochron asymmetry of abyssal hill character in response to ridge segmentation. Along the EPR, abyssal hills appear to change in response to the upwelling struc- 
ture and consequent variation in mantle temperature beneath a ridge segment, with smaller rms height toward the middle of a segment and larger rms height toward the ends [Goff, 1991; Goff et al., 1993]. Along northern EPR segments, characteristic width and aspect ratio tend to find their maximum and minimum, respectively, toward the middle of the segment [Goff, 1991]. Along southern EPR segments, little or no along-isochron variation in either characteristic width or aspect ratio is observed [Goff et al. 1993]. In contrast to these EPR observations, inside-outside corner asymmetries appear to dominate abyssal hill development within segments of the slow spreading MAR [Tucholke et al., 1992; Tucholke and Lin, 1994]. This is clearly documented in along-axis variation in abyssal hill rms height, characteristic width, and aspect ratio (Figures 4-6).

The different character of MAR and EPR abyssal hills in relation to ridge segmentation is very similar to differences in other geologic and geophysical parameters. Only MAR segments display significant inside-outside corner asymmetry in elevation, gravity signature, apparent crustal thickness, and bulk composition [Tucholke and Lin, 1994]. This asymmetry is thought to be caused by low-angle, detachment faulting in the slow spreading MAR crust [Dick et al., 1981; Karson and Dick, 1983, 1984; Karson, 1990; Tucholke and Lin, 1994]. Two implications of the detachment model which will affect inside-outside corner surface morphology can be considered in the context of our observations. First, crustal thickness will have an effect on the mechanical strength of the lithosphere, and in particular, thicker crust may result in weaker lithosphere [e.g., Shaw and Lin, 1994]. From simplified theoretical work relating faulting and morphology to lithospheric strength [e.g., Malinverno and Cowie, 1993; Shaw and Lin, 1993], we would predict faults with larger throw and wider spacing (and consequently larger and wider abyssal hills) on thinned, inside corner crust, which is consistent with our observations. Second, volcanic edifices are likely to be more common on outside corner crust (hanging wall of detachment fault) than on inside corner crust [Tucholke and Lin, 1994]. Because rms heights increase from outside corners (more volcanic) to inside corners (less volcanic), it appears that roughness created by faulting must dominate over roughness created by volcanoes.

\section{Division of the South Segment}

B. Tucholke et al. (manuscript in preparation, 1995) have identified a small-offset, secondary discontinuity spanning crustal ages 29-21 Ma within the south segment. This raises a question about the suitability of treating data from both north and south of this boundary as observations from a single segment. It is interesting, however, that over the full run of the south segment, there is a positive trend in rms height going from north to south (from outside to inside corner; Figures 11a-11d, 11e). Thus the south segment, as defined by the larger-offset discontinuities at its northern and southern margins, has behaved overall as a complete inside-outside corner system throughout its history. Superpimosed on the positive trend of rms height in the 29-25 Ma and 25-21 Ma age bins we do see a small but consistent negative step which seems to be associated with the crossing from inside to outside corner across the secondary discontinuity (Figures 11a and $11 \mathrm{~b}$ ). Thus it appears that even such minor offsets may influence lithospheric properties that control faulting and abyssal hill formation, although the influence is reduced as offset length is reduced.

The small negative step in rms height within the interior of the south segment persists through crustal ages 21-17 Ma, despite the lack of any discordance in crustal geomorphology, gravity, or magnetics. Whether this persistence is somehow related to the prior secondary discontinuity or to some other unrelated factor is presently unknown. We believe that the complex structure of the rms height variations seen in the 17-12 Ma and 12-7 Ma age bins (Figures $11 \mathrm{~d}$ and 11e) are related to the propagator pseudofaults traversing those regions (Figure $2 \mathrm{~b}$ ).

\section{Abyssal Hills, Crustal Thickness, and Axial Mantle Temperature}

As with intrasegment variations in abyssal hill morphology, intersegment and along-flow-line variations can be correlated to variations in relative crustal thickness inferred from RMBA (Figures 10 and 12). Both correlations indicate that larger, wider abyssal hills are generated in thinner crust, suggesting that lithospheric strength, as modulated by crustal thickness, plays a primary role in controlling extensional faulting and the resulting abyssal hill size and shape. However, while it is hypothesized that inside-outside comer asymmetry in crustal thickness is a result of tectonic thinning by low-angle detachment faulting [Dick et al., 1981; Brown and Karson, 1988; Karson, 1990; Tucholke and Lin, 1994], intersegment and flow line variations in crustal thickness likely result from spatial variations [Lin et al., 1990] and temporal variations [Tucholke and Lin, 1994], respectively, in axial mantle temperature and magmatism. Thus axial thermal structure, either directly or indirectly, may also control the character of abyssal hills. The effects of crustal thickness and axial mantle temperature are expected to be similar: Either lower axial mantle temperature [e.g., McNutt, 1984] or a thinner crust associated with reduced melt generation in the presence of lower temperatures would imply greater lithospheric strength. It is therefore difficult to separate the two effects.

An apparent correlation of abyssal hill structure with axial thermal structure is also observed within segments at the EPR, but there is little variation between segments. RMS heights on EPR flanks tend to be smallest toward the middle of segments and increase toward the ends; this is a pattern which correlates with the inferred focusing of mantle upwelling beneath the ridge axis [Goff, 1991; Cochran et al., 1993; Goff et al., 1993]. MAR abyssal hills also may be influenced by focused mantle upwelling beneath ridge segments, but if so, this signal is mostly obscured by the inside-outside corner asymmetry. The small minimum in rms height and more significant minimum in characteristic width in the near-axis swaths of the south segment (Figures 4 and 5) may be one example of abyssal hill formation responding to inside-outside corner asymmetry superimposed on focused mantle upwelling. We anticipate that as the average temperature of the mantle at the axis increases, abyssal hill formation will respond more to mantle upwelling and less to the factors controlling inside-outside corner asymmetry.

\section{Abyssal Hills and Faulting}

Two kinds of circumstantial evidence have been presented in the results and above discussion favoring the assertion that normal faulting, as opposed to volcanic edifice formation, is the principal abyssal hill forming process at slow spreading rates: (1) Assuming the validity of the detachment model (in particular, that volcanic edifices are more common on outside corner crust), inside-outside corner asymmetry in abyssal hill characteristics (rms heights are larger on inside corner crust) can only be accounted for if faulted morphology is much larger than volcanic edifice morphology; and (2) fault density (as interpreted from side scan sonar data) computed within the center of each segment correlates with colocated estimates of statistical parameters (negatively with both rms height and characteristic width and positively with aspect ratio) in the near-axis (low sediment) regions. We note that the latter evidence could have other explanations. For example, in the event that volcanism were dominant, faulting could be controlled by the locations of volcanic edifices, and the corre- 
lation between statistical parameters and fault density could be an artifice of the separate correlation of each with volcanic edifice formation. However, we believe the first evidence is a strong constraint and sufficient for our interpretation; the second evidence does not contradict this interpretation.

Whether MAR abyssal hills are generated predominantly by faulting or volcanic processes has been debated vigorously in the literature (see also Goff [1991] and Shaw and Lin [1993] for more extensive discussion and references). Rona et al. [1974] concluded from a study of abyssal hills east of the MAR near $23^{\circ} \mathrm{N}$ that both volcanic and tectonic processes play an important role in their formation. Kong et al. [1988] and Pockalny et al. [1988] observed that a large volcanic edifice which formed in the rift valley near $23^{\circ} \mathrm{N}$ was similar in size and shape to abyssal hill structures off axis and thus proposed that abyssal hills in this region are extinct volcanic edifices which have been rafted away. However, before a volcanic edifice can be transferred to the ridge flank, it must pass over the rift mountains, and in the process, it is subjected to extensive normal faulting with individual fault throws of the order of hundreds of meters [Macdonald and Luyendyk, 1977]. Smith and Cann [1990] suggest that such faulting so drastically alters surface morphology that volcanic edifices constructed within the median valley can no longer be identified as distinct features following the faulting process. While many volcanic features may exit the rift valley relatively intact [Jaroslow et al., 1994], these earlier studies, like our data, are consistent with the assertion that normal faulting is the dominant abyssal hill forming mechanism.

\section{Conclusions}

Our principal results of the statistical analysis and related interpretations are as follows:

1. As suggested by Tucholke et al. [1992] and Tucholke and Lin [1994], abyssal hill morphology is strongly influenced by the inside-outside corner geometry of slow spreading mid-ocean ridge segments. This is evident in our near-axis data sets, where abyssal hills originating at inside corners have larger rms height and characteristic width, and smaller plan view aspect ratios than abyssal hills originating at outside corners (Figures 4-6). Insideoutside corner asymmetry in abyssal hill morphology may be a direct consequence of tectonic thinning of inside comer crust by low-angle detachment faulting [Dick et al., 1981; Karson, 1990; Tucholke and Lin, 1994].

2. There is an overall positive trend in rms height going from outside to inside corner crust over the full 29-m.y. run of the south segment. Within this positive trend is a slight negative step in rms height near the middle of the segment in the 29-25 Ma, 25$21 \mathrm{Ma}$, and 21-17 Ma age bins (Figures 11a-11c). In the 29-25 $\mathrm{Ma}$ and 25-21 Ma age bins, this step correlates with the outside to inside corner transition associated with a small-offset secondary discontinuity (Figures 2,11a, and 11b). Thus just as there is a hierarchy of offset magnitude and bathymetric expression of ridge axis discontinuities, there may be a correlative hierarchy of effects on development of abyssal hills adjacent to the discontinuities.

3. Residual mantle Bouger anomalies correspond positively with both intersegment and flow line variations in abyssal hill rms height and characteristic width and negatively with plan view aspect ratio (Figures 10 and 12). Lower-relief, narrower, and more lineated abyssal hills are produced when the crust being generated is thicker (i.e., when the mantle beneath the axis is hotter), and higher, wider, less lineated abyssal hills are produced when the crust being generated is thinner (i.e., when the mantle beneath the axis is colder). This suggests that in addition to responding to differences in mechanisms of crustal accretion at in- side and outside corners, abyssal hill morphology also responds to temporal and intersegment variations in crustal thickness and/or thermal structure at the axis.

4. Assuming the validity of the detachment model, insideoutside corner asymmetry in abyssal hill characteristics can only be accounted for if faulted morphology is much larger than volcanic edifice morphology. This interpretation is consistent with the observation that in near-axis data, fault density (as determined from analysis of HMR1 side scan imagery) correlates negatively with variations in both $\mathrm{mms}$ height and characteristic width and positively with variations in aspect ratio. However, these correlations are not generally observed off axis along the run of the south segment. This may be attributable to sediment cover.

Acknowledgments. This research was supported by the Office of Naval Research under grants N00014-92-J-1214, N00014-94-I-0197, N0014-90-J-1621, and N0014-94-1-0466. G.E.J, was supported by ONR AASERT grant N00014-93-I-1153, and additional support to J.L. was provided by NSF grant OCE93-00708. We are indebted to M. Orr, J. Kravitz, and M. Badiey for their support in development of the research plan for the ONR Atlantic Natural Laboratory. We also thank T. Reed and $P$. Lemmond for their efforts in processing and display of the Hydrosweep data on which this study was based and to the crew and scientific party on Ewing Cruise 9208 for their assistance in data acquisition and processing. Thoughtful reviews from M. Cannat, J. Karson, and an anonymous associate editor on an earlier draft helped improve this manuscript considerably. UTIG contribution 1154 . WHOI contribution 9004 .

\section{References}

Bell, T. H., Statistical features of sea-floor topography, Deep Sea Res., 22, 883-892, 1975.

Bell, T. H., Mesoscale sea floor roughness, Deep Sea Res., 26A, 65-76, 1978.

Blackman, D. K., and D. W. Forsyth, Isostatic compensation of tectonic features of the Mid-Atlantic Ridge: $25^{\circ}-27^{\circ} 30^{\prime}$ S, J. Geophys. Res., 96 , 11,741-11,758, 1991.

Brown, J. R., and J. A. Karson, Variations in axial processes on the MidAtlantic Ridge: The median valley of the MARK area, Mar. Geophys. Res., 10, 109-138, 1988.

Chayes, D. N., D. W. Caress, W. B. F. Ryan, A. Malinverno, W. Menke, and C. Keely, Status of Hydrosweep on the R/V Ewing: System operation and data processing (abstract), Eos Trans. AGU, 72 (44), Fall Meet. suppl., 488, 1991.

Cochran, J. R., J. A. Goff, A. Malinverno, D. J. Fomari, C. Keeley, and $X$. Wang, Morphology of a "superfast" mid-ocean ridge crest and flanks: The East Pacific Rise, $7^{\circ}-9^{\circ} \mathrm{S}$, Mar. Geophys. Res., 15, 65-75, 1993.

Detrick, R. S., H. D. Needham, and V. Renard, Gravity anomalies and crustal thickness variations along the Mid-Atlantic Ridge between $33^{\circ} \mathrm{N}$ and $40^{\circ} \mathrm{N}, J$. Geophys. Res., 100, 3767-3787, 1995.

Dick, H. J. B., G. Thompson, and W. B. Bryan, Low-angle faulting and steady state emplacement of plutonic rocks at ridge-transform intersections (abstract), Eos, Trans. AGU, 62, 406, 1981.

Escartin, J., and J. Lin, Ridge offsets, normal faulting, and gravity anomalies of slow spreading ridges, J. Geophys. Res., 100, 6163-6177, 1995.

Fox, C. G., and D. E. Hayes, Quantitative methods for analyzing the roughness of the seafloor, Rev. Geophys., 23, 1-48, 1985.

Gilbert, L. E., and A. Malinverno, A characterization of the spectral density of residual ocean floor topography, Geophys. Res. Lett., 15, 1401-1404, 1988.

Goff, J. A., Stochastic modeling of seafloor morphology, Ph.D. thesis, 266 pp., Mass. Inst. of Technol./Woods Hole Oceanogr. Inst., Cambridge, 1990.

Goff, J. A., A global and regional stochastic analysis of near-ridge abyssal hill morphology, J. Geophys. Res., 96, 21,713-21,737, 1991.

Goff, J. A., Quantitative characterization of abyssal hill morphology along flow lines in the Atlantic Ocean, J. Geophys. Res., 97, 91839202, 1992.

Goff, J. A., and T. H. Jordan, Stochastic modeling of seafloor morphology: Inversion of Sea Beam data for second-order statistics, $J$. Geophys. Res., 93, 13,589-13,608, 1988. 
Goff, J. A., and T. H. Jordan, Stochastic modeling of seafloor morphology: Resolution of topographic parameters by Sea Beam data, IEEE J. Oceanic Eng., 14, 326-337, 1989.

Goff, J. A., A. Malinverno, D. J. Fornari, and J. R. Cochran, Abyssal hill segmentation: quantitative analysis of the East Pacific Rise flanks $7^{\circ} \mathrm{S}$ $9^{\circ} \mathrm{S}, J$. Geophys. Res., 98, 13,851-13,862, 1993.

Hayes, D. E., and K. A. Kane, The dependence of seafloor roughness on spreading rate, Geophys. Res. Lett., 18, 1425-1428, 1991.

Jaroslow, G. E., D. K. Smith, and B. E. Tucholke, The off-axis record of volcanism in the westem North Atlantic Ocean (abstract), EosTrans. $A G U, 75$ (44), Fall Meet. suppl., 660-661, 1994.

Karson, J. A., Seafloor spreading on the Mid-Atlantic Ridge: Implications for the structure of ophiolites and oceanic lithosphere produced at slow spreading environments, in Proceedings of the Symposium TROODOS 1987, edited by J. Malpas et al., pp. 547-555, Geol. Surv. Dep., Nicosia, Cyprus, 1990.

Karson, J. A., and H. J. B. Dick, Tectonics of ridge-transform intersections at the Kane Fracture Zone, Mar. Geophys. Res., 6, 51-98, 1983.

Karson, J. A., and H. J. B. Dick, Deformed and metamorphosed oceanic crust on the Mid-Atlantic Ridge, Ofioliti, 9, 279-302, 1984.

Kong, L. S. L., R. S. Detrick, P. J. Fox, L. A. Mayer, and W. B. F. Ryan, The morphology and tectonics of the MARK area from Sea Beam and Sea MARC I observations (Mid-Atlantic Ridge $23^{\circ} \mathrm{N}$ ), Mar. Geophys. Res., 10, 59-90, 1988.

Krause, D. C., and H. W. Menard, Depth distribution and bathymetric classification of some seafloor profiles, Mar. Geol., 3, 169-193, 1965.

Kuo, B.-Y., and D. W. Forsyth, Gravity anomalies of the ridge-transform system in the South Atlantic between 31 and $34.5^{\circ} \mathrm{S}$ : Upwelling centers and variations in crustal thickness, Mar. Geophys. Res., 10, 205-232, 1988.

Lin, J., and J. Phipps Morgan, The spreading rate dependence of threedimensional mid-ocean ridge gravity structure, Geophys. Res. Lett., 19 13-16, 1992.

Lin, J. G., M. Purdy, H. Schouten, J.-C. Sempere, and C. Zervas, Evidence from gravity data for focused magmatic accretion along the Mid-Atlantic Ridge, Nature, 344, 627-632, 1990.

Lin, J., B. E. Tucholke, M. C. Kleinrock, and J. A. Goff, Variations in crustal faulting and magmatic accretion along the Mid-Atlantic Ridge and off-axis: Results from the western flank of the MAR at 25-27 deg N (abstract), Eos Trans. AGU, 73 (43), Fall Meet. suppl., 538, 1992.

Macdonald, K. C., and B. P. Luyendyk, Deep-tow studies of the structure of the Mid-Atlantic Ridge near lat $37^{\circ}$ N., Geol. Soc. Am. Bull., 88, 621-636, 1977

Malinvemo, A., Inverse square-root dependence of mid-ocean-ridge flank roughness on spreading rate, Nature, 352, 58-60, 1991.

Malinverno, A., and P. A. Cowie, Normal faulting and the topographic roughness of mid-ocean ridge flanks, J. Geophys. Res., 98, 17,92117,935, 1993.

Malinverno, A., and L. E. Gilbert, A stochastic model for the creation of abyssal hill topography at a slow spreading center, J. Geophys. Res., 94, 1665-1675, 1989.

Malinverno, A., and R. A. Pockalny, Abyssal hill topography as an indicator of episodicity in crustal accretion, Earth Planet. Sci. Lett., $99,154-169,1990$

McDonald, M. F., and E. J. Katz, Quantitative method for describing the regional topography of the ocean floor, J. Geophys. Res., 74, 2597$2607,1969$.

McNutt, M. K., Lithospheric flexure and thermal anomalies, J. Geophys. Res., 89, 11,180-11,194, 1984.

Menard, H. W., Sea floor spreading, topography and the second layer, Science, 157, 923-924, 1967.

Menard, H. W., and J. Mammerickx, Abyssal hills, magnetic anomalies and the East Pacific Rise, Earth Plan. Sci. Lett., 2, 465-472, 1967.

Neumann, G. A., and D. W. Forsyth, High resolution statistical estimation of seafloor morphology: Oblique and orthogonal fabric on the flanks of the Mid-Atlantic Ridge, $34^{\circ}-35.5^{\circ} \mathrm{S}$, Mar. Geophys. Res., in press, 1995.

Phipps Morgan, J., and D. W. Forsyth, Three-dimensional flow and temperature perturbations due to a transform offset: Effects on oceanic and upper mantle structure, J. Geophys. Res., 93, 2955-2966, 1988.
Phipps Morgan, J., E. M. Parmentier, and J. Lin, Mechanisms for the origin of mid-ocean ridge axial topography: Implications for the thermal and mechanical structure of accreting plate boundaries, $J$. Geophys. Res., 92, 12,823-12,836, 1987.

Pockalny, R. A., R. S. Detrick, and P. J. Fox, Morphology and tectonics of the Kane transform from Sea Beam bathymetry data, J. Geophys. Res., 93, 3179-3193, 1988.

Press, W. H. B. P. Flannery, S. A. Teukolsky, and W. T. Vetterling, Numerical Recipes, 701 pp., Cambridge Univ. Press, Cambridge, Mass., 1989.

Rona, P. A., R. N. Harbison, and S. A. Bush, Abyssal hills of the eastern central North Atlantic, Mar. Geol., 16, 275-292, 1974.

Scheirer, D. S., and K. C. Macdonald, Variation in cross-sectional area of the axial ridge along the East Pacific Rise: Evidence for the magmatic budget of a fast spreading center, J. Geophys. Res., 98, 7871-7885, 1993.

Schouten, H., and C. Denham, Deconvolution of faulted normal seafloor in the North Atlantic FAMOUS area (abstract), Eos Trans. AGU, 64 $314,1983$.

Severinghaus, J. P., and K. C. Macdonald, High inside comers at ridgetransform intersections, Mar. Geophys. Res., 9, 353-367, 1988.

Shaw, P. R., Ridge segmentation, faulting, and crustal thickness in the Atlantic Ocean, Nature, 358, 490-493. 1992.

Shaw, P. R., and J. Lin, Causes and consequences of variations in faulting style at the Mid-Atlantic Ridge, J. Geophys. Res., 98, 21,839-21,851, 1993.

Shaw, W. J., and J. Lin, Three-dimensional modelling of thermomechanical structure of oceanic spreading centers: Effects of alongaxis thickness variations associated with segmentation and hot spots (abstract), Eos Trans. AGU, 75 (16), Spring Meet. suppl., 331, 1994.

Smith, D. K., and J. Cann, Hundreds of small volcanoes on the median valley floor of the Mid-Atlantic Ridge at $24^{\circ} \cdot 30^{\circ} \mathrm{N}$, Nature, 348, 152 $155,1990$.

Sparks, D. W., E. M. Parmentier, and J. Phipps Morgan, Three dimensional mantle convection beneath a segmented spreading center: Implications for along-axis variations in crustal thickness and gravity, J. Geophys. Res., 98, 21,977-21,995, 1993.

Su, W., C. Z. Mutter, J. C. Mutter, and W. R. Buck, Some theoretical predictions on the relationships among spreading rate, mantle temperature, and crustal thickness, J. Geophys. Res., 99, 3215-3227, 1994.

Tucholke, B. E., and J. Lin, A geologic model for the structure of ridge segments in slow-spreading ocean crust, J. Geophys. Res., 99, 11,937$11,958,1994$.

Tucholke, B. E., and H. Schouten, Kane fracture zone, Mar. Geophys. Res. $10,1-39,1988$

Tucholke, B. E., and P. R. Vogt, Western North Atlantic: Sedimentary evolution and aspects of tectonic history, Initial Rep. Deep Sea Drill Proj., 43, 791-825, 1979.

Tucholke, B. E., J. Lin, and M. C. Kleinrock, Crustal structure of spreading segments on the western flank of the Mid-Atlantic Ridge at $25^{\circ} 25^{\prime} \mathrm{N}$ to $27^{\circ} 10^{\prime} \mathrm{N}$ (abstract), Eos Trans. $A G U, 73$ (43), Fall Meeting Suppl., 537-538, 1992.

Wang, $X$., and J. R. Cochran, Gravity anomalies, isostasy, and mantle flow at the East Pacific Rise crest, J. Geophys. Res., 98, 19,50519,532, 1993.

Webb, H. F., and T. H. Jordan, Quantifying the distribution and transport of pelagic sediments on young abyssal hills, Geophys. Res. Lett., 20, 2203-2206, 1993.

J. A. Goff, University of Texas Institute for Geophysics, 8701 North MoPac Expressway, Austin, TX 78759-8397. (e-mail: goff@utig.ig.utexas.edu)

G. E. Jaroslow, J. Lin, and B. E. Tucholke, Woods Hole Oceanographic Institution, Woods Hole, MA 02153.

M. C. Kleinrock, Box 6214 Station B, Vanderbilt University, Nashville, TN 37235 .

(Received October 3, 1994; revised August 3, 1995;

accepted August 10, 1995) 